\title{
Short Communication \\ Blood pressure and renal cancer risk: the HUNT Study in Norway
}

\author{
LJ Vatten*,', D Trichopoulos², J Holmen' and TIL Nilsen' \\ 'Department of Public Health, Faculty of Medicine, Nonwegian University of Science and Technology, Trondheim, Nonway; ${ }^{2}$ Department of Epidemiology, \\ Harvard University School of Public Health, Boston, USA
}

In a prospective study of 36728 women and 35688 men during I 8 years of follow-up, compared to systolic pressure $<130 \mathrm{~mm} \mathrm{Hg}$, levels of $130-149,150-169$ and $\geqslant 170 \mathrm{~mm} \mathrm{Hg}$ in women were associated with relative risks of renal cell cancer of I.7, 2.0 and 2.0, respectively ( $P$ for linear trend, $0.1 \mathrm{I})$. In men, there was no association with blood pressure. British Journal of Cancer (2007) 97, I I2- I 14. doi: I0.1038/sj.bjc.6603823 www.bjcancer.com

Published online 22 May 2007

(c) 2007 Cancer Research UK

Keywords: renal cell cancer; blood pressure; antihypertensive treatment; population study; epidemiology

The association of blood pressure with risk of renal cell cancer has been investigated in a number of cohort (Fraser et al, 1990; Grove et al, 1991; Coughlin et al, 1997; Heath et al, 1997; Chow et al, 2000; Choi et al, 2005; Flaherty et al, 2005; Fryzek et al, 2005; Lindgren et al, 2005; Schouten et al, 2005) and case-control (McLaughlin et al, 1995; Yuan et al, 1998; Shapiro et al, 1999) studies, using as principal exposure variable either recorded blood pressure or reported hypertension. In men, recorded blood pressure has shown a convincing exposure-response gradient related to renal cell cancer risk (Coughlin et al, 1997; Chow et al, 2000). In women, however, only reported history of hypertension has been studied as the main exposure variable. In one cohort (Flaherty et al, 2005) and two case-control studies (Yuan et al, 1998; Shapiro et al, 1999), history of hypertension was associated with increased risk. Documenting the presence or the lack of an exposure-response gradient in women is important, and might promote a better probing of the underlying mechanism of the association.

In this prospective study of 36728 women and 35688 men, we report on the association of blood pressure measured at baseline with renal cell cancer risk during 18 years of follow-up, together with that related to ever use of blood pressure medication.

\section{MATERIALS AND METHODS}

In 1984, 85100 individuals were invited to the Nord Trøndelag Health Study (the HUNT Study) in Norway, and 75058 (88.2 percent) accepted the invitation, filled in a self-administered questionnaire, and attended a clinical examination (Holmen et al, 1991; Ellekjaer et al, 2000). Briefly, information included smoking status and standardised measurements of blood pressure, body height and weight. The study was approved by the Regional Committee for Ethics in medical research, and by the Norwegian Data Inspectorate.

This study was restricted to participants without prevalent cancer who had complete information on blood pressure and body

*Correspondence: Professor LJ Vatten, Department of Public Health, Faculty of Medicine, NTNU, NO-7489 Trondheim, Norway.

E-mail: lars.Vatten@ntnu.no

Received 28 February 2007; revised 2 May 2007; accepted 2 May 2007; published online 22 May 2007 mass index. Blood pressure was measured using calibrated mercury manometers with standard cuff size (Holmen et al, 1991). We divided systolic pressure (in $\mathrm{mm} \mathrm{Hg}$ ) into the following categories: $<130$ (reference), 130-149, 150-169 and $\geqslant 170$, and diastolic pressure (in $\mathrm{mm} \mathrm{Hg}$ ) into the following: $<85$ (reference), $85-94,95-104$ and $\geqslant 105$. Information on use of antihypertensive medication was derived from the question 'do you use or have you ever used blood pressure medication?'

Body mass index was calculated as weight (in $\mathrm{kg}$ ) divided by the squared value of height (in metres), and grouped into four categories: $<18.5,18.5-24.9,25-29.9$ and $\geqslant 30$. Information on smoking was categorised as never, former or currently smoking. Education was divided into three categories, depending on duration $(<9,10-12$ and $>12$ years).

The mandatory reporting of cancer by physicians and hospitals to the Cancer Registry of Norway (www.kreftregisteret.no) provides information on incident cases of renal cell cancer that occurred during follow-up. Person-years were calculated from the clinical examination until the diagnosis of renal cell cancer or other cancers (except basal cell carcinoma), death from other causes, or the end of follow-up, 31 December 2002, whichever came first. The relative risk was calculated as the rate of renal cell cancer within a given blood pressure category compared with that in the reference category. We used Cox regression analysis to adjust for potential confounding by body mass index, smoking, use of blood pressure medication and education level. The statistical analyses were conducted using STATA, version 9.0 (StataCorp LP, 1985-2005).

\section{RESULTS}

During 18 years of follow-up, 94 women and 144 men were diagnosed with renal cell cancer. Characteristics of the cohort are shown in Table 1. Risk was much lower in women with systolic pressure below $130 \mathrm{~mm} \mathrm{Hg}$ than for those with higher levels, after adjustment for age, body mass index, smoking status, use of blood pressure medication and education (Table 2). Compared to the reference $(<130 \mathrm{~mm} \mathrm{Hg})$, the adjusted relative risk in women with systolic pressure $130-149 \mathrm{~mm} \mathrm{Hg}$ was 1.7 (95\% confidence interval (CI), 0.9-3.5), with levels $150-169 \mathrm{~mm} \mathrm{Hg}$ the risk was $2.0(95 \%$ 
Table I Characteristics of the study population (36728 women and 35688 men), stratified by systolic blood pressure categories

\begin{tabular}{|c|c|c|c|c|c|c|c|c|}
\hline \multirow{2}{*}{ Characteristic } & \multicolumn{4}{|c|}{ Women } & \multicolumn{4}{|c|}{ Men } \\
\hline & \multicolumn{4}{|c|}{ Systolic blood pressure } & \multicolumn{4}{|c|}{ Systolic blood pressure } \\
\hline No. of participants & 17745 & 9251 & 5292 & 4440 & 12209 & 14333 & 5954 & 3192 \\
\hline No. of renal cell cancers & 13 & 26 & 24 & 22 & 31 & 40 & 35 & 18 \\
\hline Median person years (range) & $18(19)$ & $18(19)$ & $17(19)$ & $13(19)$ & $18(19)$ & $18(19)$ & $17(19)$ & $10(19)$ \\
\hline Body mass index, $\% \geqslant 25.0 \mathrm{~kg} \mathrm{~m}^{-2}$ & 25 & 52 & 64 & 70 & 37 & 51 & 62 & 62 \\
\hline Smoking status, \% current & 34 & 23 & 15 & 10 & 32 & 29 & 26 & 24 \\
\hline Educational level, $\% \geqslant 13$ years & 11 & 5 & 2 & 1 & 13 & 10 & 5 & 3 \\
\hline
\end{tabular}

Table 2 Relative risk of renal cell cancer associated with standardised measured blood pressure and self reported blood pressure medication

\begin{tabular}{|c|c|c|c|c|c|c|c|c|c|c|}
\hline \multirow[b]{2}{*}{ Variable } & \multicolumn{5}{|c|}{ Women } & \multicolumn{5}{|c|}{ Men } \\
\hline & Person years & Cases & $\mathbf{R R}^{\mathbf{a}}$ & $95 \% \mathrm{Cl}$ & $P_{\text {trend }}{ }^{b}$ & Person years & Cases & $\mathbf{R R}^{\mathbf{a}}$ & $95 \% \mathrm{Cl}$ & $P_{\text {trend }}{ }^{b}$ \\
\hline \multicolumn{11}{|c|}{ Systolic blood pressure $(\mathrm{mm} \mathrm{Hg})$} \\
\hline$<130$ & 304754 & 13 & 1.0 & (Reference) & - & 200863 & 31 & 1.0 & (Reference) & - \\
\hline $130-149$ & 145513 & 26 & 1.7 & $(0.9-3.5)$ & - & 223960 & 40 & 0.8 & $(0.5-1.4)$ & - \\
\hline $150-169$ & 73828 & 24 & 2.0 & $(0.9-4.2)$ & - & 81183 & 35 & 1.2 & $(0.7-2.0)$ & - \\
\hline$\geqslant 170$ & 53060 & 22 & 2.0 & $(0.9-4.6)$ & 0.11 & 33890 & 18 & 1.0 & $(0.5-1.9)$ & 0.59 \\
\hline \multicolumn{11}{|c|}{ Diastolic blood pressure $(\mathrm{mm} \mathrm{Hg})$} \\
\hline$<85$ & $346610^{\circ}$ & 31 & 1.0 & (Reference) & - & 264778 & 41 & 1.0 & (Reference) & - \\
\hline $85-94$ & 145246 & 22 & 0.8 & $(0.5-1.5)$ & - & 173219 & 56 & 1.6 & $(1.0-2.3)$ & - \\
\hline $95-104$ & 64349 & 22 & 1.4 & $(0.8-2.5)$ & - & 76975 & 20 & 1.0 & $(0.6-1.7)$ & - \\
\hline$\geqslant 105$ & 20950 & 10 & 1.6 & $(0.8-3.5)$ & 0.13 & 24924 & 7 & 0.9 & $(0.4-2.0)$ & 0.49 \\
\hline \multicolumn{11}{|c|}{ Blood pressure medication ${ }^{c}$} \\
\hline No & $504 \mid 35$ & 57 & 1.0 & (Reference) & - & 499677 & 106 & 1.0 & (Reference) & - \\
\hline
\end{tabular}

$\mathrm{Cl}=$ confidence interval, $\mathrm{RR}=$ relative risk. ${ }^{\mathrm{a}}$ Adjusted for age, blood pressure medication (no, yes), body mass index (<I8.5, I8.5-24.9, 25.0-29.9, $\geqslant 30.0$ ), smoking status (never, former, current, unknown), education ( $<10,10-12, \geqslant 13$ years, unknown). ${ }^{b} P$-values from trend test using the categories as an ordinal variable in the Cox regression model. ' Adjusted for age, body mass index ( $<18.5,18.5-24.9,25.0-29.9, \geqslant 30.0)$, smoking status (never, former, current, unknown), education ( $<10,10-12, \geqslant 13$ years, unknown).

CI, 0.9-4.2), and with levels $\geqslant 170 \mathrm{~mm} \mathrm{Hg}$, it was 2.0 (95\% CI, $0.9-$ 4.6). For diastolic pressure, the association with renal cancer risk was weaker than for systolic. Compared to the reference $(<85 \mathrm{~mm}$ $\mathrm{Hg})$, the adjusted relative risk in women with diastolic pressure $\geqslant 105 \mathrm{~mm} \mathrm{Hg}$ was 1.6 (95\% CI, 0.8-3.5).

In a separate analysis restricted to people who reported neveruse of blood pressure medication at baseline, there was a strong and positive association between systolic pressure and risk among women (Table 3). Thus, the adjusted relative risk in women with systolic pressure $\geqslant 170 \mathrm{~mm} \mathrm{Hg}$ compared with $<130 \mathrm{~mm} \mathrm{Hg}$ was 3.4 (95\% CI, 1.3-8.9), and it showed a significant trend with increasing systolic pressure ( $P$ for trend, 0.001 ); diastolic pressure among never users of blood pressure medication, however, showed similar associations to the overall results.

Use of antihypertensive medication, as reported by women at baseline, showed a weak positive association (adjusted relative risk, 1.4, 95\% CI, 0.8-2.2, Table 2). In men, there was no clear association with systolic or diastolic blood pressure (Tables 2 and 3), and none between blood pressure medication and risk (Table 2).

\section{DISCUSSION}

The most striking finding in this study was that normotensive systolic blood pressure among women $(<130 \mathrm{~mm} \mathrm{Hg})$ was associated with consistently lower risk for renal cell cancer than higher levels. No previous study of women has assessed the effect of measured blood pressure on this risk, but a positive association with recorded blood pressure has been found among men (Coughlin et al, 1997; Chow et al, 2000).

Correspondingly, studies of antihypertensive medication, or history of hypertension, have not shown consistent results. In two prospective studies, antihypertensive treatment was associated with higher risk of renal cell cancer (Fraser et al, 1990; Heath et al, 1997), but others found no association (Grove et al, 1991; Flaherty et al, 2005; Schouten et al, 2005). One large study linking prescriptions and cancer registration in Denmark indicated that antihypertensive medication may increase risk, but was interpreted as being due to confounding by underlying hypertension (Fryzek et al, 2005). One prospective study (Flaherty et al, 2005) and two case-control studies (Yuan et al, 1998; Shapiro et al, 1999) have also reported positive associations with a history of hypertension.

Contrary to previous evidence, we found that measured blood pressure, or use of blood pressure medication, was not associated with risk for renal cell cancer among men. The reason for this discrepancy is not obvious, but may be the play of chance.

In our study, systolic and diastolic blood pressures were measured according to standardised procedures by a team of trained nurses. The cohort consists of the majority of adults in a stable, homogeneous population in Norway, well suited for cancer 
Table 3 Relative risk of renal cell cancer associated with standardised measured blood pressure among participants without blood pressure medication

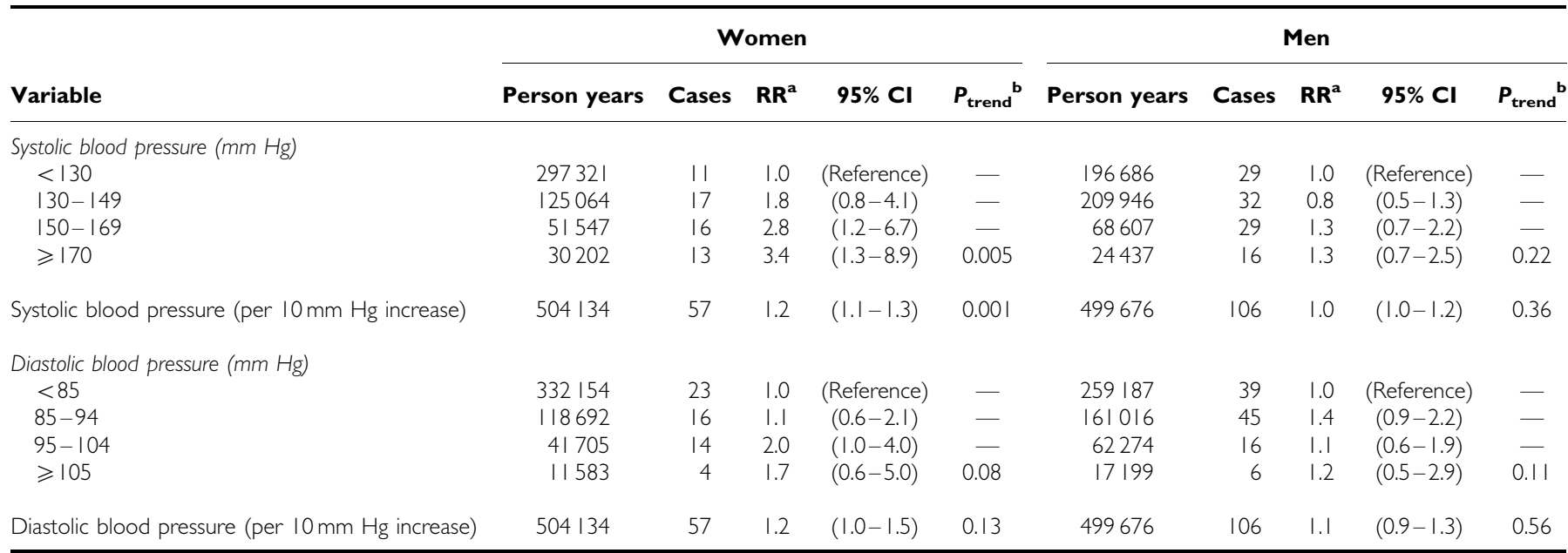

$\mathrm{Cl}=$ confidence interval, $\mathrm{RR}=$ relative risk. ${ }^{a}$ Adjusted for age, body mass index $(<\mid 8.5,18.5-24.9,25.0-29.9, \geqslant 30.0)$, smoking status (never, former, current, unknown), education $\left(<10,10-12, \geqslant 13\right.$ years, unknown). ${ }^{b}$-values from trend test using the categories as an ordinal variable in the Cox regression model

follow-up, because of the national mandatory reporting system, and the unique identification number allocated to each citizen.

Angiogenic and other growth factors are associated with blood pressure increase, and may also be involved in the development of renal cell cancer (Schena et al, 1999; Chow et al, 2000; Choueiri et al, 2006). Thus, subtle long-term influences on renal function may lead to hypertension and also be related to tumour growth. The findings raise the possibility that high blood pressure may be a cause of renal cell cancer.

\section{REFERENCES}

Choi MY, Jee SH, Sull JW, Nam CM (2005) The effect of hypertension on the risk for kidney cancer in Korean men. Kidney Int 67: 647-652

Choueiri TK, Bukowski RM, Rini BI (2006) The current role of angiogenesis inhibitors in the treatment of renal cell carcinoma. Semin Oncol 33: $596-606$

Chow WH, Gridley G, Fraumeni Jr JF, Jarvholm B (2000) Obesity, hypertension, and the risk of kidney cancer in men. $N$ Engl J Med 343: $1305-1311$

Coughlin SS, Neaton JD, Randall B, Sengupta A (1997) Predictors of mortality from kidney cancer in 332547 men screened for the Multiple Risk Factor Intervention Trial. Cancer 79: 2171-2177

Ellekjaer H, Holmen J, Ellekjaer E, Vatten L (2000) Physical activity and stroke mortality in women. Ten year follow-up of the Nord Trøndelag health survey, 1984-1986. Stroke 31: 14-18

Flaherty KT, Fuchs CS, Colditz GA, Stampfer MJ, Speizer FE, Willett WC, Curhan GC (2005) A prospective study of body mass index, hypertension, and smoking and the risk of renal cell carcinoma (United States). Cancer Causes Control 16: 1099-1106

Fraser GE, Phillips RL, Beeson WL (1990) Hypertension, antihypertensive medication and risk of renal carcinoma in California Seventh-Day Adventists. Int J Epidemiol 19: $832-838$

Fryzek JP, Poulsen AH, Johnsen SP, McLaughlin JK, Sørensen HT, Friis S (2005) A cohort study of antihypertensive treatments and risk of renal cell cancer. Br J Cancer 92: 1302-1306

Grove JS, Nomura A, Severson RK, Stemmermann GN (1991) The association of blood pressure with cancer incidence in a prospective study. Am J Epidemiol 134: 942-947

\section{ACKNOWLEDGEMENTS}

This study was financially supported by a grant from the Norwegian Research Council. There is no conflict of interest related to this work. Contributors: LJV and DT had the original idea, analysed and interpreted the data, and wrote the paper. $\mathrm{JH}$ initiated the study cohort and interpreted the results. TILN did the statistical analyses and interpreted the results. LJV has access to the data and is guarantor for the study.
Heath Jr CW, Lally CA, Calle EE, McLaughlin JK, Thun MJ (1997) Hypertension, diuretics, and antihypertensive medications as possible risk factors for renal cell cancer. Am J Epidemiol 145: 607-613

Holmen J, Forsen L, Hjort PF, Midthjell K, Waaler HT, Bjørndal A (1991) Detecting hypertension: screening versus case finding in Norway. BMJ 302: $219-222$

Lindgren AM, Nissinen AM, Tuomilehto JO, Pukkala E (2005) Cancer pattern among hypertensive patients in North Karelia, Finland. J Hum Hypertens 19: $373-379$

McLaughlin JK, Chow WH, Mandel JS, Mellemgaard A, McCredie M, Lindblad P, Schlehofer B, Pommer W, Niwa S, Adami HO (1995) International renal-cell cancer study. VII. Role of diuretics, other anti-hypertension medications and hypertension. Int $J$ Cancer 63: $216-221$

Schena FP, Strippoli GF, Wankelmuth P (1999) Renal growth factors: past, present, and future. Am J Nephrol 19: 308-312

Schouten LJ, van Dijk BA, Oosterwijk E, Hulsbergen-van de Kaa CA, Kiemeney LA, Goldbohm RA, Schalken JA, van den Brandt PA (2005) Hypertension, antihypertensives and mutations in the Von HippelLindau gene in renal cell carcinoma: results from the Netherlands Cohort Study. J Hypertens 23: $1997-2004$

Shapiro JA, Williams MA, Weiss NS, Stergachis A, LaCroix AZ, Barlow WE (1999) Hypertension, antihypertensive medication use, and risk of renal cell carcinoma. Am J Epidemiol 149: 521-530

Yuan JM, Castelao JE, Gago-Dominguez M, Ross RK, Yu MC (1998) Hypertension, obesity and their medications in relation to renal cell carcinoma. Br J Cancer 77: 1508-1513 